\title{
Identification of Disruptions and Associated Resilience Strategies in Blood Supply Chain Using a New Combined Approach
}

\author{
Ali Sibevei ${ }^{1} \mathbb{D},{\text { Adel } \text { Azar }^{2}}^{(D}$, Mostafa Zandieh $^{3} \mathbb{D}$ \\ Date of submission: 2 Apr, 2020 Date of acceptance: 3 Aug, 2020
}

\begin{abstract}
INTRODUCTION: Supply chains face various disruptions from human-made to natural disasters preventing proper flow of materials and products. This problem is more important in the healthcare supply chains, especially the blood supply chains, in which human lives are at risk. Making the supply chains resilient, recently addressed by managers and researchers, can be a good way to tackle them. This study aimed to identify the most important disruptions and associated resilience strategies in the blood supply chain of Tehran, Iran, and prioritize the identified strategies based on the disruptions.

METHODS: In the current study, important disruptions and associated appropriate resilience strategies were determined using previous studies and Delphi method. Then, the most important resilience strategies were identified and prioritized proposing the House of Quality and Importance-Performance Analysis (IPA) as a novel hybrid approach.

FINDINGS: A total of 9 disruptions and 16 resilience strategies were determined by reviewing previous studies and asking for expert opinions. The suggested hybrid model also contributed to determining the importance of each strategy in addressing disruptions and prioritizing them in the blood supply chain of Tehran.

CONCLUSION: Those strategies with high importance and low performance, such as flexibility or risk management culture, are of great importance and should be considered by managers and improved according to IPA. In addition, other strategies, such as social responsibility or redundancy, should be continued in the current way.
\end{abstract}

Original Article

Keywords: Blood Supply Chain; Disruption; House of Quality; Importance-Performance Analysis; Resilience.

How to cite this article: Sibevei A, Azar A, Zandieh M. Identification of Disruptions and Associated Resilience Strategies in Blood Supply Chain Using a New Combined Approach. Sci J Rescue Relief 2020; 12(2): 102-112.

\section{Introduction}

I ran is exposed to various natural and manmade disruptions. The human-related consequences of disasters and their impact on healthcare service delivery have made this issue very important (1). On the other hand, rapid changes, increased uncertainty, environmental fluctuations, and unexpected risks have increased the likelihood of severe disruptions in the supply chains (2). These disruptions can affect organizational performance (3). Over the past two decades, several destructive events, such as financial or economic crises, natural disasters, or supplier bankruptcies, have put organizations at risk (4). For example, the earthquake, tsunami, and subsequent nuclear crisis in Japan in 2011 caused Toyota to reduce production to 40,000 units and lose 72 million dollars of profit a day (5). Such disasters disrupt supply chains (6).

The likelihood of the above-mentioned events

1-PhD Student, Faculty of Management and Economics, Tarbiat Modares University, Tehran, Iran.

2- PhD, Faculty of Management and Economics, Tarbiat Modares University, Tehran, Iran.

3- PhD, Faculty of Management and Accounting, Shahid Beheshti University, Tehran, Iran.

Correspondence to: Adel Azar, Email: azara@modares.ac.ir

102 Sci J Rescue Relief 2020; Volume 12; Issue 2 
is very low and difficult to predict (7). However, if they occur, they will have a significant impact on businesses (8). Supply chain disruptions are unplanned and unpredictable events interrupting the normal flow of products and materials in the supply chain (9). They are caused by various factors, such as natural disasters, fires, loss of suppliers, wars, and terrorist attacks (7).

Disruption in the healthcare supply chain means an unwanted event that can make it difficult to deliver services (10). Disruptions, such as earthquakes, floods, hurricanes, and other hazards, affect many countries and resources around the world, although this impact will be greater in countries that are populated, less prepared, and fragile. This has encouraged international organizations, such as the World Health Organization and United Nations, to launch campaigns (e.g., hospitals safe from disasters) to promote attention toward protecting healthcare facilities from natural hazards (11). Therefore, in recent years, disruption management of the supply chain has become one of the most important concerns of many organizations and managers (12) leading researchers to address disruptions by creating resilient supply chains (13).

Resilience can be defined as the ability of a system to return to its normal state or move to a new and more desirable state after a disruption (14). The resilience of organizations and their supply chains has become a common point of interest among many researchers. This interest has been due to the effects of disruptions on company levels in the short and long term (15).

Resilience in healthcare services is more important than production because failure to deliver on-time services to patients can have lethal effects (11). Healthcare is usually the first thing coming to the mind when dealing with the consequences of major hazards (16). Although the supply chain and disasters have recently received more attention, there have been a limited number of studies to simultaneously address both disasters and healthcare supply chain (17).

Considering the vital role of blood, the management of blood supply chain disruption is very important. A major challenge for public health systems around the world is to provide adequate health and blood during disasters (18). A disaster in blood transfusion services indicates a situation in which the ability of the supply chain to receive and supply blood temporarily or completely stops. In other words, a condition causing sudden or more than usual demand for blood products in hospitals and problems for the blood collection system (19). Therefore, disruptions in the blood supply chain lead to disasters that can cause injury, destruction, loss of life, human suffering, or deterioration in the supply chain (20). These disasters illustrate the way disruptions can affect the performance of the blood supply chain and operational services (6). Consequently, it is important to try to appropriately respond to these catastrophes using resilience strategies (21).

Studies carried out on supply chain resilience are increasing, and many of these studies address various issues of supply chain vulnerability and risk (22). In this regard, some studies $(23,24)$ have applied mathematical modeling. Several studies identified resilience factors and strategies in the supply chain by using approaches, such as SWOT analysis, literature review, and focus group $(25,26)$. However, there have been a limited number of studies on the resilience of the blood supply chain.

Alora and Barua identified and prioritized the risks associated with disruptions in the Indian supply chain. The first stage involves the identification and finalization of supply chain disruption risks through literature review and expert opinion using the Delphi method. In addition, the second stage includes the extraction of the relationships between risk factors using interpretive structural modeling (ISM) (27). Tang studied robust strategies for the reduction of supply chain disruptions and presented robust strategies with two properties (28). Chowdhury et al. used the analytic hierarchy process (AHP) and quality function deployment (QFD) to identify and prioritize vulnerabilities related to supply chain resilience (29).

An extensive literature review was carried out by Sangari and Dashtpeyma to build a comprehensive set of supply chain resilience strategies in which ISM and fuzzy network analysis were used to analyze identified factors (30). Bradaschia and Pereira examined the strategy of flexibility in the supply chain in a hospital and attempted to investigate the resilience of the supply chain with this strategy (31). According to the results of a study carried out by Mandal on the effect of organizational culture dimensions on supply chain resilience, culture can 
have positive effects in this regard (16).

A review of the literature indicates that several studies have investigated supply chain disruptions and their impacts on supply chain performance. However, a few of them have examined supply chain strategies in controlling disruptions in the blood supply chain. Therefore, the determination of the disruptions and resilience strategies of the blood supply chain would be useful in increasing resilience in this regard. In addition, the relationship between these strategies with disruptions and effect of each of these strategies on disruptions is also an important subject. Therefore, the present study aimed to answer the following questions:

1. What are the common disruptions in a blood supply chain?

2. What are resilience strategies to cope with these disruptions?

3. How to relate disruptions and resilience strategies and prioritize them?

Importance-Performance Analysis (IPA) is suggested in order to answer the abovementioned questions. However, the conventional IPA did not clearly identify the importance of strategies; therefore, the House of Quality (HOQ) concepts were used to measure the importance of strategies. Some studies used a variety of approaches to improve IPA, such as a modified IPA based on partial correlation analysis and natural logarithmic transformation (32), combination of IPA and Decision-Making Trial and Evaluation Laboratory (33), IPA and Kano model (34), and combination of IPA and fuzzy sets, to reinforce IPA model (35).

The major difference between the present study and the above-mentioned studies is that none of the studies used the concepts of the HOQ to determine the importance of variables in IPA. In fact, in addition to studying the major disruptions and strategies of resilience in the blood supply chain, the innovation of the current study is the development of a new hybrid HOQIPA approach. Firstly, research methodology is described in the following sections, and then the findings of the study are reported. Finally, discussion and conclusion are presented.

\section{Methods}

The purpose of this study was to investigate the disruptions of the blood supply chain and analyze the associated resilience strategies. A review of the literature and the Delphi method were used for the identification of the blood supply chain disruptions and effective strategies. Then, the IPA approach was adopted to prioritize the identified strategies. Therefore, it was possible to investigate the position of each blood supply chain strategy based on its performance and importance. It is very important to evaluate the importance of strategies in terms of their role in controlling the disruptions; however, in the conventional IPA, the importance of the strategy is determined using a questionnaire regardless of the effectiveness of the strategy in controlling the disruptions. Therefore, the concepts of the HOQ were used to determine the importance of strategies. In other words, the importance of strategies is determined through their effectiveness in controlling disruptions.

In the present study, the selection of experts was conducted using purposive sampling. Out of different managers in the blood supply chain of Tehran, Iran, 11 experts were chosen in order to employ the Delphi method and examine the relationships between strategies and disruptions in the HOQ. Each part of the methodology is explained in the following sections.

Importance-Performance Analysis

The IPA was introduced by Martilla and James as a method for the development of effective marketing programs (36). Organizations can examine different types of quality attributes based on each of the four quadrants in the IPA matrix and formulate strategies and plans.

\section{Developed-IPA methodology}

Proposed IPA steps in the present study are similar to those of typical IPA except that the degree of importance was determined using the HOQ concepts in the second step.

Step 1: This step identifies the strategies related to blood supply chain disruptions. In this study, disruptions and resilience strategies were identified using a literature review and the Delphi method. The experts were 11 members of the blood supply chain with more than 15 years of experience.

Step 2: This step is the determination of the degree of importance and performance of each factor. In the present study, the performance and importance of each strategy were measured by a questionnaire and the HOQ, respectively.

In the HOQ model, a set of requirements (i.e., WHATs) and responses (i.e., HOWs) are 
Table 1. Values of relationships in House of Quality

\begin{tabular}{|c|c|}
\hline Symbol & Value \\
\hline 0 & 9 \\
0 & 3 \\
$\Delta$ & 1 \\
Blank & 0 \\
\hline
\end{tabular}

expressed, and each response can satisfy one or more requirements. One of the steps in the HOQ is the relationship matrix, used to determine the relationships between disruptions (i.e., WHATs) and resilience strategies (i.e., HOWs) (37). As previously mentioned, the current study used the relationship matrix to determine the importance of strategies; accordingly, each strategy had a relationship to the disruption or could be used to deal with that. In this matrix, the relationships between disruptions and resilience strategies are considered a strong relationship (9), normal relationship (3), weak relationship (1), and no relationship (0). Table 1 depicts the symbols of the aforementioned relationships (37).

For the determination of the importance of strategies using the HOQ following steps are taken:

A. This step identifies the disruptions that may occur in the blood supply chain. This is performed by reviewing the literature and asking for expert opinions. These disruptions fall into the matrix rows (i.e., HOWs) in accordance with the HOQ matrix as shown in Table 2.

B. This step determines the strategies using a literature review and expert opinions. The important point is that more than one strategy can be dealt with a disruption. These strategies are placed in the column of WHATs as presented in Table 2.

C. This step identifies the relationship between each strategy and disruptions. Then, the importance of each strategy is calculated by summing the relationships specified in the matrix.
Step 3: In this step, the opinions of all decision-makers are integrated using the geometric mean. Therefore, $b_{j}$ is the final value of importance, and $c_{j}$ is the final value of performance (38). As a result, there will be one degree of importance and one degree of performance for each strategy.

Step 4: This step determines the threshold value. The threshold value is used to determine the IPA matrix quadrants. The arithmetic mean is utilized for the determination of the threshold value. The threshold values of importance and performance are represented by $\mu_{b}$ and $\mu_{c}$, respectively, as follows:

$\mu_{b}=\frac{\sum_{j=1}^{m} b_{j}}{m}, \mu_{c}=\frac{\sum_{j=1}^{m} c_{j}}{m}$

where $m$ is the number of resilience strategies to cope with disruptions.

Step 5: This step constructs the IPA matrix and determines the relative position of each strategy on the matrix. There are four quadrants as follows:

"Concentrate here" representing the strategies of high importance and low performance "Maintain" representing the strategies of high importance and high performance

"Possible overkill" representing the strategies of low importance and high performance

"Lower priority" representing the strategies of low importance and low performance (39)

Step 6: This step determines the priority of each strategy for improvement. The gap between the importance value and performance of the $\mathrm{j}$ strategy multiplied by the importance value can represent the weight of the $\mathrm{j}$ strategy. The weight of the $\mathrm{j}$ strategy is denoted by $\mathrm{OWj}$.

$O W_{j}=\left|\left(b_{j}-c_{j}\right) \times b_{j}\right|$

Then, normalization is performed for ease of analysis as follows:

Table 2. Relationship matrix of House of Quality

\begin{tabular}{|c|c|c|c|c|c|c|}
\hline \multirow{6}{*}{$\begin{array}{c}\text { Blood supply } \\
\text { chain strategies } \\
\text { (HOWs) }\end{array}$} & \multicolumn{5}{|c|}{ Disruptions in the blood supply chain (WHATs) } & \multirow{2}{*}{$\begin{array}{l}\text { Strategy } \\
\text { importance }\end{array}$} \\
\hline & & Disruption 1 & Disruption 2 & ... & Disruption i & \\
\hline & Strategy 1 & $\triangle$ & 0 & & 0 & b1 \\
\hline & Strategy 2 & & & 0 & & b2 \\
\hline & & & $\triangle$ & & 0 & \\
\hline & & $\triangle$ & & 0 & & \\
\hline & & & 0 & 0 & $\triangle$ & \\
\hline & Strategy m & & 0 & $\triangle$ & 0 & $\mathrm{Bm}$ \\
\hline
\end{tabular}


$s w_{j}=\frac{o w_{j}}{\sum_{j=1}^{m} o w_{j}}, \quad 0 \leq s w_{j} \leq 1, \quad \sum_{j=1}^{m} s w_{j}=1$

As a result, those with higher $s w_{j}$ should be given higher priority for improvement (38).

\section{Findings}

Considering the IPA steps, the results are presented in this section.

Step 1: According to the expert opinions and literature review, 9 disruptions (Table 3) and 16 resilience strategies of the blood supply chain (Table 4) were identified. They were finalized using the Delphi method in three rounds.

The definition and explanation of the resilience strategies are presented as follows:

1-Redundancy: It means maintaining the capacity to respond to disruptions in the supply chains, which is mostly performed by investing in capacity and capital before it is required (54). The strategic use of capacity and surplus inventory that can be used in times of crisis, such as shortages or increased demands (14). Since this strategy is costly, it should be used when the disruption is predictable or likely to last for a short time (8).

2- Flexibility: Flexibility is the most frequently used strategy, based on the literature, for the reduction of supply chain disruptions (40). Flexibility is the ability of a company to respond flexibly to fundamental or long-term changes in the supply chain or market environment by adjusting the supply chain configuration (55). Datta et al. stated that flexibility is needed in all parts of the supply chain (56). With infrastructures, such as flexible transportation systems, flexible manufacturing facilities, and flexible capacity, organizations can increase the degree of resilience in their supply chains $(30,57)$.

3- Information sharing: Researchers working on supply chain resilience have repeatedly

Table 3. Disruptions of blood supply chain

\begin{tabular}{|c|c|}
\hline Disruption & Resource \\
\hline Terrorist attacks & $(14,40,41)$ \\
Cyber-attacks and & $(42,43)$ \\
hacking & $(42,44)$ \\
Cut-off of suppliers & $(41,42,45)$ \\
Street riots & $(44,46,47,48,49)$ \\
Strikes & $(27,40,42,43,45,50)$ \\
Wars & $(14,40,51)$ \\
Earthquakes & $(42,43,45)$ \\
Severe climate changes & $(41,42,52,53)$ \\
Contagious diseases &
\end{tabular}

emphasized the importance of effective knowledge management and information sharing as key strategies for the development of resilience (2, $30)$. It can reduce supply chain uncertainty and vulnerability to disruptions (2). Information sharing means that team members collectively utilize available information resources (58). This strategy and collaboration among different entities in the supply chain are prerequisites for the achievement of visibility (2).

4- Collaboration: It is the ability to effectively work with other entities for mutual benefits (30). Collaboration between different groups can help effectively manage risks (13).

5- Visibility: Visibility is the ability to be perceived by the eye or the mind. Supply chain visibility is about information concerning the entities and events determining orders, inventories, shipments, and distribution to any events in the environment (59). Increasing the visibility of demand information across the supply chain reduces risks (60).

6- Agility: Agility is defined as the ability of an organization supply chain to quickly respond to unpredictable changes in demand and supply (2, 14, 61). Agility is the ability to efficiently change operating conditions to respond to the uncertain environment or volatile market conditions (40).

7- Anticipation: It is the ability to detect potentially damaging future events (25). Supply chain operational managers should anticipate disruptions and prepare the supply chain for any expected and unexpected changes (57). In some studies, anticipation is also mentioned as sensing (62). This capability prepares organizations to

Table 4. Resilience strategies of blood supply chain

\begin{tabular}{|c|c|}
\hline Strategy & Reference \\
\hline Redundancy & $(8,14,54,55)$ \\
Flexibility & $(30,40,55,56,57)$ \\
Information sharing & $(2,30,58)$ \\
Collaboration & $(13,30,55)$ \\
Visibility & $(60,61)$ \\
Agility & $(2,14,40,55,62)$ \\
Anticipation & $(25,30,57,62,65)$ \\
Risk management culture & $(14,63)$ \\
Security & $(25,61,64,65,66)$ \\
Lean and efficient & $(25,67,68)$ \\
Use of information technology & $(61)$ \\
Financial strength & $(25,54,66)$ \\
Dispersion & $(25,54,60)$ \\
Quality management & $(68,69)$ \\
Human resource management & $(25,70)$ \\
Social responsibility & Experts \\
\hline
\end{tabular}


cope with the negative impacts of future events, thereby making the supply chain resilient (30).

\section{8- Risk Management Culture in the Supply}

Chain: As many organizations have recognized that the only way to implement total quality management was to create its culture in order for everyone to have a quality concern, today it is required to create a risk management culture (14). Therefore, risk management should be embedded in the organizational culture of any company (63), and this includes support of the organization's senior management, especially in critical issues (61).

9- Security: It is the protection against intentional disruptions, such as thefts, terrorist attacks, and cyber-attacks $(25,61)$. The purpose of the security strategy is to increase supply chain capability for the identification of suspicious and unusual elements (64). In this regard, secure information is provided to all stakeholders for the prevention of attacks and intrusions (65). Security is an essential feature of any supply chain and should be predesigned to reduce the occurrence of disruptions (66).
10- Lean and Efficient: Efficiency is meant to produce outputs with the least resources (25) and have low wastage to fully meet anticipated demand (67). The adoption of lean approaches leads to reduce waste and increase productivity (68).

11- Use of Information Technology capabilities: Information technology (IT) can enhance communication and support for other resilience strategies (61) due to the importance expressed separately.

12- Financial strength: It means the ability to deal with financial fluctuations (25).

13- Dispersion: This means decentralizing resources and customers (25). Decentralization allows local communities to be more responsive and reduce the risk of disruption despite an increase in costs (50).

14. Quality Management: Some studies pointed out that quality management and control in addition to related tools and approaches can lead to resilience (68), especially for products that are perishable, such as foods (69).

15. Human Resource Management: More emphasis is placed on nurturing multi-skilled

Table 5. Importance of strategies using House of Quality

\begin{tabular}{|c|c|c|c|c|c|c|c|c|c|c|c|}
\hline \multirow[b]{2}{*}{ Strategy } & \multirow[b]{2}{*}{$\begin{array}{c}\text { Terrorist } \\
\text { attacks }\end{array}$} & \multirow[b]{2}{*}{$\begin{array}{l}\text { Cyber-attacks } \\
\text { and hacking }\end{array}$} & \multirow[b]{2}{*}{$\begin{array}{l}\text { Cut-off of } \\
\text { suppliers }\end{array}$} & \multirow[b]{2}{*}{$\begin{array}{c}\text { Street } \\
\text { riots }\end{array}$} & \multicolumn{3}{|c|}{ Disruption } & \multirow[b]{2}{*}{$\begin{array}{c}\text { Severe climate } \\
\text { changes }\end{array}$} & \multirow[b]{2}{*}{$\begin{array}{c}\text { Contagious } \\
\text { diseases }\end{array}$} & \multirow[b]{2}{*}{ Score } & \multirow[b]{2}{*}{$\begin{array}{c}\text { Normalized } \\
\text { score }\end{array}$} \\
\hline & & & & & Strikes & Wars & Earthquakes & & & & \\
\hline Redundancy & 3 & 3 & 9 & 3 & 9 & 3 & 9 & 3 & 3 & 45 & 8.54 \\
\hline Flexibility & 1 & 3 & 9 & 3 & 9 & 9 & 9 & 3 & 3 & 49 & 9.30 \\
\hline Collaboration & 3 & 1 & 3 & 1 & 3 & 9 & 9 & 1 & 9 & 39 & 7.40 \\
\hline Visibility & 1 & 9 & 3 & 1 & 0 & 3 & 3 & 1 & 1 & 22 & 4.17 \\
\hline Agility & 3 & 9 & 3 & 3 & 3 & 3 & 3 & 9 & 1 & 37 & 7.02 \\
\hline $\begin{array}{l}\text { Information } \\
\text { sharing }\end{array}$ & 3 & 3 & 3 & 1 & 1 & 3 & 3 & 0 & 3 & 20 & 3.80 \\
\hline Anticipation & 1 & 9 & 9 & 3 & 0 & 3 & 3 & 9 & 3 & 40 & 7.59 \\
\hline $\begin{array}{c}\text { Risk } \\
\text { management } \\
\text { culture }\end{array}$ & 3 & 3 & 3 & 3 & 9 & 3 & 3 & 3 & 9 & 39 & 7.40 \\
\hline Security & 9 & 9 & 0 & 3 & 1 & 9 & 9 & 0 & 1 & 41 & 7.78 \\
\hline $\begin{array}{l}\text { Lean and } \\
\text { efficient }\end{array}$ & 1 & 0 & 3 & 1 & 0 & 3 & 3 & 3 & 3 & 17 & 3.23 \\
\hline $\begin{array}{c}\text { Use of } \\
\text { information } \\
\text { technology }\end{array}$ & 1 & 9 & 1 & 0 & 1 & 3 & 3 & 3 & 3 & 24 & 4.55 \\
\hline $\begin{array}{l}\text { Financial } \\
\text { strength }\end{array}$ & 1 & 3 & 9 & 0 & 9 & 9 & 3 & 1 & 1 & 36 & 6.83 \\
\hline Dispersion & 3 & 0 & 0 & 3 & 1 & 9 & 9 & 3 & 1 & 29 & 5.50 \\
\hline $\begin{array}{c}\text { Quality } \\
\text { management }\end{array}$ & 1 & 3 & 3 & 1 & 0 & 3 & 3 & 1 & 9 & 24 & 4.55 \\
\hline $\begin{array}{c}\text { Human } \\
\text { resource } \\
\text { management }\end{array}$ & 1 & 1 & 0 & 1 & 9 & 3 & 3 & 1 & 1 & 20 & 3.80 \\
\hline $\begin{array}{c}\text { Social } \\
\text { responsibility }\end{array}$ & 3 & 0 & 0 & 3 & 3 & 9 & 9 & 9 & 9 & 45 & 8.54 \\
\hline
\end{tabular}


human resources and reforming the system based on the conditions of inexperienced employees (70). It also includes the improvement of human resource structures and policies (25).

16. Spreading social responsibility among individuals: Soni et al. describe one of the resilience strategies as corporate social responsibility (13). However, it can also be expressed among individuals. Expanding social responsibility is one of the common ways to increase donations (71). Steel et al. stated that raising donor social responsibility can have a positive effect on blood donation behavior (72).

Step 2: This step is the determination of the importance and performance of each strategy. As noted, the HOQ was used to determine the importance of strategies regarding their relation- ships with the blood supply chain disruptions. It should be indicated that the numbers were normalized for an easier understanding of the importance of strategies in the matrix. Expert performance evaluation strategies were obtained using a usual IPA questionnaire.

Step 3: The importance and performance values of blood supply chain resilience strategies and their rankings are presented in Table 6 .

Step 4: The threshold values of importance and performance are listed in the bottom row of Table 6. These values are used in drawing the IPA matrix.

Step 5: In this step, the importance and performance matrix is plotted according to the threshold value and importance and performance values of each strategy in Figure 1.

Table 6. Importance and performance values

\begin{tabular}{|c|c|c|c|c|c|}
\hline Strategy & Code & Importance & Performance & Normalized weight & Ranking \\
\hline Flexibility & S2 & 9.30 & 2.8 & 0.234 & 1 \\
\hline Social responsibility & S16 & 8.54 & 5.1 & 0.114 & 2 \\
\hline Risk management culture & S8 & 7.40 & 3.6 & 0.110 & 3 \\
\hline Anticipation & S7 & 7.59 & 4.0 & 0.106 & 4 \\
\hline Security & S9 & 7.78 & 4.4 & 0.102 & 5 \\
\hline Redundancy & S1 & 8.54 & 6.3 & 0.074 & 6 \\
\hline Collaboration & S3 & 7.40 & 5.2 & 0.064 & 7 \\
\hline Agility & S5 & 7.02 & 5.0 & 0.054 & 8 \\
\hline Financial strength & S12 & 6.83 & 4.9 & 0.052 & 9 \\
\hline Quality management & S14 & 4.55 & 6.8 & 0.040 & 10 \\
\hline Lean and efficient & S10 & 3.23 & 4.8 & 0.020 & 11 \\
\hline Human resource management & S15 & 3.80 & 4.7 & 0.014 & 12 \\
\hline Visibility & S4 & 4.17 & 4.7 & 0.008 & 13 \\
\hline Use of information technology & S11 & 4.55 & 4.9 & 0.006 & 14 \\
\hline Dispersion & S13 & 5.50 & 5.4 & 0.003 & 15 \\
\hline Information sharing & S6 & 3.80 & 3.7 & 0.001 & 16 \\
\hline Threshold value & & 6.25 & 4.76 & & \\
\hline
\end{tabular}

\section{IPA MAP}

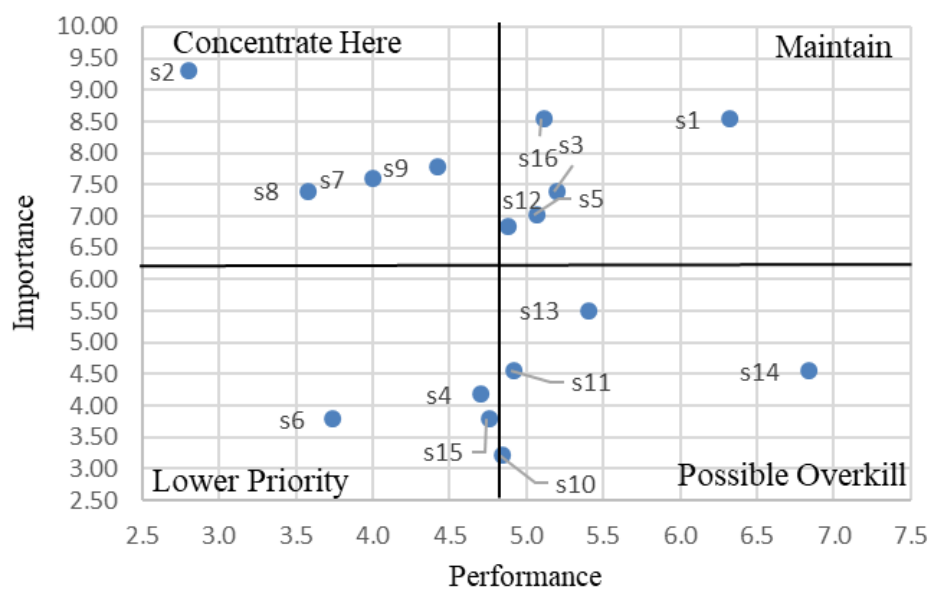

Figure 1. Importance and performance matrix 
As illustrated in Figure 1, the strategies of redundancy (S1), agility (S5), collaboration (S3), social responsibility (S16), and financial strength (S12) are in the "Maintain" quadrant. In other words, these strategies are of great importance in controlling the disruptions with high performance in the supply chain; therefore, they had to be preserved as they were. Anticipation (S7), security (S9), risk management culture (S8), and flexibility (S2) are in the "Concentrate here" quadrant indicating that despite their high importance they are not well implemented, thereby requiring to be invested and improved. Dispersion (S13), quality management (S14), IT (S11), and lean and efficient (S10) are of little importance but performed well. As a result, given their low importance in controlling disruptions effectively, they did not require more investment, and some of the costs and resources spent on these strategies needed to be used for other strategies, especially the "Concentrate here" quadrant strategies.

Human resource management (S15), information sharing (S6), and visibility (S4) are in the "Lower priority" quadrant. In other words, given their role in controlling disruptions, they are of low performance; however, due to their low importance, there was no need for investment to improve their performance.

Step 6: In order to prioritize strategies for improvement, the weight of each strategy was calculated using formula 2 and normalized using formula 3 and is presented in the fourth column of Table 6. According to the results in Table 6, it is suggested to focus on the improvement of "Concentrate here" quadrant strategies based on the weight calculated for each strategy, namely flexibility (S2), risk management culture (S8), anticipation (S7), and security (S9).

\section{Discussion and Conclusion}

With the spread of disruptions in different supply chains, strategies for dealing with them are increasing. Resilience strategies have received the attention of researchers and managers recently using methods such, as QFD and AHP (29) or ISM and fuzzy analytic network process (30). However, less attention has been paid to these disruptions and their coping strategies in the healthcare supply chains, especially the blood supply chains. To the best of our knowledge, the combined method used in the present study has been never used in other studies. Therefore, the present study investigated appropriate resilience strategies to deal with disruptions in the blood supply chain using a new hybrid method of IPA and HOQ and prioritized each strategy after the identification of their importance and performance.

According to the results of the current study, the strategies at the bottom had lower importance in this supply chain; nevertheless, some of them have been paid attention in other supply chains, such as visibility $(60,61)$. In the "Maintain" quadrant, unlike the strategies, such as financial strength $(25,45)$ or redundancy $(8,14,54)$, social responsibility was not mentioned in other studies. Strategies to focus on in the "Concentrate here" quadrant include flexibility $(30,40,45)$, risk management culture $(14,63)$, security $(61,64$, $65)$, and anticipation $(25,30,67)$. The strategies that fall into this quadrant should be given more attention.

For example, flexibility in the resilience literature has been cited as one of the most important strategies for dealing with disruptions (40). Infrastructures, such as a flexible transportation system in different parts of the supply chain from blood collection centers to blood centers and distribution to hospitals or various types of vehicles (e.g., helicopters), can help the network to be flexible in different situations. According to the equipment of the Iranian Blood Transfusion Organization, it is required to collaborate with other organizations, such as the Iranian Red Crescent Society or municipalities. Although these collaborations occur in times of disaster, their protocols, processes, and prerequisites should be specified in advance.

In addition, given the current situation, managers should monitor various parts of the supply chain and provide sufficient flexibility in processes, blood centers, and suppliers. Due to the problems and situations existing under sanctions, special attention should be paid to suppliers' flexibility. In this regard, multi-sourcing is one of the common ways.

Another important issue is creating a risk management culture in the supply chain ensuring that all the members of the organization have embraced supply chain risk management, especially the management of the organization. 
Some of the blood supply chain managers do not have a management background; therefore, senior managers need to become more familiar with the concept of risk management and how to spread the culture across the supply chain. Holding risk management courses for the staff at different levels can also be beneficial. Overall, the whole supply chain should perceive the importance of risk management in their working life.

Only with regard to the HOQ, some points can be concluded. Some strategies are good for particular disruptions and are not suitable for others. For example, expanding individuals' social responsibility is one of the useful strategies in some disruptions, such as severe climate change or contagious diseases (e.g., coronavirus disease 2019). In these situations, a sense of compassion and responsibility can help a great deal in addressing blood shortage. However, how to expand this issue and cause the donor to remain loyal are other subjects beyond the scope of this study. The flexibility of the supply chain to provide some special methods and circumstances can also be beneficial.

It is recommended to carry out studies to further investigate strategies that are ranked in each quadrant by categorizing the strategies of each quadrant according to different criteria using multi-criteria decision-making methods. Moreover, these strategies may be related to each other, and the way a strategy affects other ones can be beneficial for managers and a good idea for future studies. Some strategies are also close to the boundaries of the quadrants, and using fuzzy numbers in the calculation of the values may improve the results. In this study, the HOQ approach was added to determine the weights of each strategy; however, further approaches can be used in future studies. In addition, if the number of disruptions is higher, the disruptions can be firstly clustered using different criteria, and then strategies are identified and appropriately prioritized for each cluster.

\section{Acknowledgments}

The authors would like to appreciate all who cooperated in conducting the study.

\section{Conflict of Interests}

The authors declare that there is no conflict of interest.

\section{References}

1. Ardalan A, Masoumi G, Goya M, Ghafari M, Miadfar J, Sarvar M, et al. Disaster health management: Iran's progress and challenges. Iran J Public Health 2009; 38(1): 93-7.

2. Ganguly A, Chatterjee D, Rao H. The role of resiliency in managing supply chains disruptions. In Supply Chain Risk Management. Singapore: Springer; 2018. P. 237-51.

3. Ho W, Zheng T, Yildiz H, Talluri S. Supply chain risk management: a literature review. Int J Product Res 2015; 53(16): 5031-69.

4. Kilubi I. Investigating current paradigms in supply chain risk management-a bibliometric study. Bus Proc Manag J 2016; 22(4): 662-92.

5. Pettit TJ, Croxton KL, Fiksel J. Ensuring supply chain resilience: development and implementation of an assessment tool. J Busin Logist 2013; 34(1): 46-76.

6. Jabbarzadeh A, Fahimnia B, Seuring S. Dynamic supply chain network design for the supply of blood in disasters: a robust model with real world application. Transport Res E Logist Transport Rev 2014; 70: 225-44.

7. Simchi-Levi D, Schmidt W, Wei Y, Zhang PY, Combs K, Ge Y, et al. Identifying risks and mitigating disruptions in the automotive supply chain. Interfaces 2015; 45(5): 375-90.

8. Sheffi Y. The resilient enterprise: overcoming vulnerability for competitive advantage. New York: Zone Books; 2007.

9. Craighead CW, Blackhurst J, Rungtusanatham MJ, Handfield RB. The severity of supply chain disruptions: design characteristics and mitigation capabilities. Decis Sci 2007; 38(1): 131-56.

10. Harvey J. Professional service supply chains. J Oper Manag 2016; 42: 52-61.

11. Achour N, Miyajima M, Pascale F, Price A. Hospital resilience to natural hazards: classification and performance of utilities. Disaster Prev Manag 2014; 23(1): 40-52.

12. Barroso AP, Machado VH, Barros AR, Machado VC. Toward a resilient supply chain with supply disturbances. 2010 IEEE International Conference on Industrial Engineering and Engineering Management, Macao, China; 2010. P. 245-9.

13. Soni U, Jain V, Kumar S. Measuring supply chain resilience using a deterministic modeling approach. Comput Ind Eng 2014; 74: 11-25.

14. Christopher M, Peck H. Building the resilient supply chain. Int J Logist Manag 2004; 15(2): 1-14.

15. Hendricks KB, Singhal VR. An empirical analysis of the effect of supply chain disruptions on longrun stock price performance and equity risk of the firm. Prod Oper Manag 2005; 14(1): 35-52.

16. Mandal S. The influence of organizational culture on healthcare supply chain resilience: moderating 
role of technology orientation. J Busin Ind Mark 2017; 32(8): 1021-37.

17. Syahrir I, Vanany I. Healthcare, and disaster supply chain: literature review and future research. Proc Manuf 2015; 4: 2-9.

18. Achour, N. Healthcare disaster risk reduction and management. Singapore: World Scientific; 2017.

19. Kohneh JN, Teymouri E, Pishvaee MS. Blood products supply chain design considering disaster circumstances (Case study: earthquake disaster in Tehran). Int J Ind Syst Eng 2016; 9: 51-72.

20. American Association of Blood Banks. Disaster operations handbook-hospital. Maryland: American Association of Blood Banks; 2008.

21. Hora M, Klassen RD. Learning from others' misfortune: Factors influencing knowledge acquisition to reduce operational risk. J Oper Manag 2013; 31(1-2): 52-61.

22. Levalle RR, Nof SY. Resilience in supply networks: definition, dimensions, and levels. Annu Rev Control 2017; 43: 224-36.

23. Xiao J, Wang F. Resilience optimization for medical device distribution networks based on node failures. Int J Supply Chain Manag 2014; 3(3): 113-20.

24. Hassani A, Khosrojerdi A. Robust global supply chain network design under disruption and uncertainty considering resilience strategies: a parallel memetic algorithm for a real-life case study. Transport Res E Logist Transport Rev 2016; 87: 20-52.

25. Pettit TJ, Fiksel J, Croxton KL. Ensuring supply chain resilience: development of a conceptual framework. J Busin Logist 2010; 31(1): 1-21.

26. Leat P, Revoredo-Giha C. Risk and resilience in agri-food supply chains: the case of the ASDA Pork Link supply chain in Scotland. Int J Supply Chain Manag 2013; 18: 219-31.

27. Alora A, Barua MK. An integrated structural modeling and MICMAC analysis for supply chain disruption risk classification and prioritization in India. Int J Value Chain Manag 2019; 10(1): 1-25.

28. Tang CS. Robust strategies for mitigating supply chain disruptions. Int J Logist Res Appl 2006; 9(1): 33-45.

29. Chowdhury MH, Dewan MN, Quaddus MA. Supply chain resilience to mitigate disruptions: a QFD approach. Hochiminh City, Vietnam: Pacific Asia Conference on Information Systems (PACIS); 2012. P. 66.

30. Sangari MS, Dashtpeyma M. An integrated framework of supply chain resilience enablers: a hybrid ISM-FANP approach. Int J Bus Excell 2019; 18(2): 242-68.

31. Bradaschia M, Pereira SC. Building resilient supply chains through flexibility: a case study in healthcare. J Oper Supply Chain Manag 2015; 8(2): 120-33.
32. Deng W. Using a revised importance-performance analysis approach: the case of Taiwanese hot springs tourism. Tour Manag 2007; 28(5): 1274-84.

33. Ho LH, Feng SY, Lee YC, Yen TM. Using modified IPA to evaluate supplier's performance: multiple regression analysis and DEMATEL approach. Expert Syst Appl 2012; 39(8): 7102-9.

34. Matzler K, Bailom F, Hinterhuber HH, Renzl B, Pichler J. The asymmetric relationship between attribute-level performance and overall customer satisfaction: a reconsideration of the importanceperformance analysis. Ind Mark Manag 2004; 33(4): 271-7.

35. Deng WJ. Fuzzy importance-performance analysis for determining critical service attributes. Int J Serv Ind Manag 2008; 19(2): 252-70.

36. Martilla JA, James JC. Importance-performance analysis. J Market 1977; 41(1): 77-9.

37. Bouchereau V, Rowlands H. Methods and techniques to help quality function deployment (QFD). Benchmarking 2000; 7: 8-20.

38. Sholeh M, Ghasemi A, Shahbazi M. A new systematic approach in new product development through integration of general morphological analysis and IPA. Decis Sci Lett 2018; 7(2): 181-96.

39. Cohen JF, Coleman E, Kangethe MJ. An importance-performance analysis of hospital information system attributes: a nurses' perspective. Int J Med Inform 2016; 86: 82-90.

40. Parast MM, Shekarian M. The impact of supply chain disruptions on organizational performance: a literature review. Revisiting supply chain risk. Berlin, Germany: Springer; 2019. P. 367-89.

41. Wagner SM, Bode C. An empirical investigation into supply chain vulnerability. J Purch Supply Manag 2006; 12(6): 301-12.

42. Torabi SA, Giahi R, Sahebjamnia N. An enhanced risk assessment framework for business continuity management systems. Saf Sci 2016; 89: 201-18.

43. Stecke KE, Kumar S. Sources of supply chain disruptions, factors that breed vulnerability, and mitigating strategies. J Mark Channels 2009; 16(3): 193-226.

44. Dolgui A, Ivanov D, Sokolov B. Ripple effect in the supply chain: an analysis and recent literature. Int J Prod Res 2018; 56(1-2): 414-30.

45. Miller HE, Engemann KJ. Resilience and sustainability in supply chains. Revisiting supply chain risk. Berlin, Germany: Springer; 2019. P. 251-63.

46. Kleindorfer PR, Saad GH. Managing disruption risks in supply chains. Prod Oper Manag 2005; 14(1): 53-68.

47. Blackhurst J, Rungtusanatham MJ, Scheibe K, Ambulkar S. Supply chain vulnerability assessment: a network based visualization and clustering analysis approach. J Purch Supply 
Manag 2018; 24(1): 21-30.

48. Zegordi SH, Davarzani H. Developing a supply chain disruption analysis model: application of colored petri-nets. Expert Syst Appl 2012; 39(2): 2102-11.

49. Güller M, Henke M. Resilience assessment in complex supply networks. Revisiting supply chain risk. Berlin, Germany: Springer; 2019. P. 73-98.

50. Chopra S, Sodhi MS. Supply-chain breakdown. MIT Sloan Manag 2004; 46(1): 53-61.

51. Tabatabaee M, Ardalan A, Abolghasemi H, Naieni KH, Pourmalek F, Ahmadi B, et al. Estimating blood transfusion requirements in preparation for a major earthquake: the Tehran, Iran study. Prehosp Disaster Med 2010; 25(3): 246-52.

52. Harland CM. Risk in complex supply chains, networks and systems. Revisiting supply chain risk. Berlin, Germany: Springer; 2019. P. 439-55.

53. Thomas B, Anania K, DeCicco A, Hamm JA. Toward resiliency in the joint blood supply chain. Rand Health Quart 2019; 8(3): 9.

54. Kochan CG, Nowicki DR. Supply chain resilience: a systematic literature review and typological framework. Int J Phys Distrib Logist Manag 2018; 48(8): 842-65.

55. Shekarian M. A literature review on the impact of antecedents of supply chain resilience on mitigating supply chain disruptions. In Conference Annual Meeting of the Decision Sciences Institute Proceedings, Chicago, IL, USA; 2018.

56. Priya Datta P, Christopher M, Allen P. Agent-based modeling of complex production/distribution systems to improve resilience. Int $\mathbf{J}$ Logist Res Appl 2007; 10(3): 187-203.

57. Kamalahmadi M, Parast MM. A review of the literature on the principles of enterprise and supply chain resilience: major findings and directions for future research. Int J Prod Econ 2016; 171: 116-33.

58. Mesmer-Magnus JR, DeChurch LA. Information sharing and team performance: a meta-analysis. J Appl Psychol 2009; 94(2): 535-46.

59. Jüttner U, Maklan S. Supply chain resilience in the global financial crisis: an empirical study. Supply Chain Manag Int J 2011; 16(4): 246-59.

60. Chopra S, Sodhi M. Reducing the risk of supply chain disruptions. MIT Sloan Manag 2014; 55(3):
72-80.

61. Tukamuhabwa B, Stevenson M, Busby J. Supply chain resilience in a developing country context: a case study on the interconnectedness of threats, strategies, and outcomes. Supply Chain Manag Int J 2017; 22: 486-505.

62. Ehrenhuber I, Treiblmaier H, Engelhardt-Nowitzki C, Gerschberger M. Toward a framework for supply chain resilience. Int J Supply Chain Oper Resil 2015; 1(4): 339-50.

63. Waters D. Supply chain risk management: vulnerability and resilience in logistics. London: Kogan Page Publishers; 2011.

64. Manuj I, Mentzer JT. Global supply chain risk management strategies. Int $\mathbf{J}$ Phys Distrib Logist Manag 2008; 38(3): 192-223.

65. De Lima FR, Da Silva AL, Godinho Filho M, Dias EM. Systematic review: resilience enablers to combat counterfeit medicines. Supply Chain Manag Int J 2018; 12(3): 117-35.

66. Karl AA, Micheluzzi J, Leite LR, Pereira CR. Supply chain resilience, and key performance indicators: a systematic literature review. Production 2018; 28: 1-16.

67. Purvis L, Spall S, Naim M, Spiegler V. Developing a resilient supply chain strategy during 'boom' and 'bust'. Prod Plan Control 2016; 27(7-8): 579-90.

68. Mensah P, Merkuryev Y. Developing a resilient supply chain. Proc Soc Behav Sci 2014; 110: 309-19.

69. Ali I, Nagalingam S, Gurd B. Building resilience in SMEs of perishable product supply chains: enablers, barriers and risks. Prod Plan Control 2017; 28(15): 1236-50.

70. Rice JB, Caniato F. Building a secure and resilient supply network. Supply Chain Manag Rev 2003; 7(5): 22-30.

71. Shaz BH, Demmons DG, Hillyer KL, Jones RE, Hillyer CD. Racial differences in motivators and barriers to blood donation among blood donors. Arch Pathol Lab Med 2009; 133(9): 1444-7.

72. Steele WR, Schreiber GB, Guiltinan A, Nass C, Glynn SA, Wright DJ, et al. The role of altruistic behavior, empathetic concern, and social responsibility motivation in blood donation behavior. Transfusion 2008; 48(1): 43-54. 